\title{
TENSIONAMENTOS NA FORMACÃO INTERCULTURAL DE PROFESSORES INDÍGENAS: UM ESTUDO DA ESCOLA XAKRIABÁ ${ }^{1}$
}

VANESSA SENA TOMAZ ${ }^{*}$

ORCID: https://orcid.org/0000-0002-4903-6405

GELSA KNIJNIK ${ }^{* *}$

ORCID: https://orcid.org/0000-0001-7827-3867

RESUMO: O artigo discute questões da formação inicial de professores indígenas na área da Educação Matemática, em um Curso de Licenciatura Intercultural. Especificamente, analisa os tensionamentos produzidos nessa formação, quando há a intenção de se estabelecer uma proposta intercultural, que considere jogos de linguagem matemáticos tradicionais - praticados, na contemporaneidade, pelo povo Xakriabá, da Aldeia Prata - como ponto de partida para o estudo da matemática escolar ocidental. Apoiado em um trabalho de campo centrado no "medir a terra pra fazer a roça", em entrevistas realizadas com professores-estudantes e com uma liderança da aldeia, o estudo aponta para a impossibilidade de um processo tradutório entre esses jogos. Argumenta que os mesmos estão associados a duas distintas racionalidades, uma marcada pela contingência e a outra pela transcendência e que ambos devem se fazer presentes na escola, com a explicitação de suas respectivas racionalidades.

Palavras chave: Educação Matemática. Educação intercultural indígena. Jogos de Linguagem matemáticos.

\section{TENSIONS IN THE INDIGENOUS INTERCULTURAL TEACHER EDUCATION: STUDY OF A XAKRIABÁ SCHOOL}

ABSTRACT: The paper discusses matters related to initial indigenous mathematics teacher education in an intercultural undergraduate course.

\footnotetext{
1 Universidade Federal de Minas Gerais, Belo Horizonte, MG, Brasil.

${ }^{2}$ Universidade do Vale do Rio dos Sinos, Porto Alegre, RS, Brasil.

"Doutora em Educação pela Universidade Federal de Minas Gerais. Professora Associada do Departamento de Métodos e Técnicas de Ensino da Universidade Federal de Minas Gerais. Coordenadora da Habilitação em Matemática do Curso de Formação Intercultural para Educadores Indigenas - FIEI-UFMG e do Projeto "A atividade matemática escolar indígena: investigando relações entre diferentes lógicas de conhecimento, na perspectiva do bilinguismo". E-mail:<vanessastomaz@gmail.com>.

" Doutora em Educação pela Universidade Federal do Rio Grande do Sul. Professora do Programa de PósGraduação em Educação da Unisinos e coordenadora do Projeto "Educação matemática e o dispositivo da tecnocientificidade" (PPGEdu/UNISINOS). E-mail:<gelsa.knijnik@gmail.com>.
} 
Specifically, it analyzes the tensions produced in this initial education, when it is intended to establish an intercultural proposal that considers traditional mathematical language games - practiced contemporarily by the Xakriabá community from Aldeia Prata - as a starting point to studying Western school mathematics. Based on a fieldwork centered on "measuring the land to prepare it", interviews conducted with teachersstudents and village leadership, this study points to the impossibility of a translation process between these games. It argues that they are associated with two distinct rationalities, one marked by contingency and the other by transcendence, and that both should be present in school, with the explanation of their respective rationalities.

Keywords: Mathematics Education; Indigenous Intercultural Education; Mathematics Language Games.

\section{INTRODUÇÃO}

Este artigo tem como propósito examinar questões da formação inicial de professores indígenas na área da Educação Matemática, no âmbito do Curso de Licenciatura em Formação Intercultural para Educadores Indígenas da Universidade Federal de Minas Gerais (UFMG). De modo mais específico, analisa os tensionamentos que emergem nessa formação, ao ser proposta uma perspectiva intercultural que articule jogos de linguagem ${ }^{2}$ matemáticos tradicionais - praticados, na contemporaneidade, pelo povo Xakriabá, da Aldeia Prata (MG) - e jogos de linguagem matemáticos praticados em sua escola. Busca, assim, contribuir para as reflexões oferecidas por estudos realizados, relacionados ao referido Curso, por pesquisadores como Gomes e Miranda (2014); Miranda (2016) e Nunes, Valadares e Silveira Junior (2017). ${ }^{3}$

As experiências vividas poruma das autoras do artigo, professora do referido Curso, vêm mostrando que algumas práticas matemáticas das escolas do povo Xakriabá - cujo currículo está orientado pelo "Método Intercultural Indutivo" (GASCHÉ, 2004) - reverberam nesse Curso de formação, gerando tensões quando perspectivas da educação intercultural são colocadas em funcionamento.

Entre as referências expressas no documento curricular para a formação oferecida no Curso, destaca-se o diálogo intercultural, que "parte do reconhecimento e da valorização dos conhecimentos tradicionais dos diversos povos indígenas em diálogo com o conhecimento acadêmico historicamente acumulado e representado pelas grandes áreas de conhecimento" (UFMG, 2009, p.17). Na habilitação em Matemática, a perspectiva metodológica que efetiva 
esse diálogo reitera a importância de as práticas tradicionais ${ }^{5}$ estarem presentes no currículo das escolas indígenas, incluindo a escola Xakriabá, e também enfatiza que, ao discutir essas práticas, tanto no curso quanto nas escolas, conteúdos da matemática escolar de matriz eurocêntrica devem ser abordados, como já vem ocorrendo com o estudo de grandezas e medidas (TOMAZ, 2012). Os estudantes do Curso, muitos deles professores nas escolas Xakriabá, expressam, de diferentes modos, a relevância de se apropriarem dos conhecimentos transmitidos pela escola "do branco", 6 tendo em vista os desafios impostos pela sociedade contemporânea.

No entanto, quando as práticas curriculares da área da Matemática são efetivamente implementadas, emergem tensionamentos. Isso porque a presença dos conhecimentos tradicionais na escola indígena e no Curso de formação tem como propósito o "envolvimento de todos [formadores/professores, estudantes e membros da comunidade] em um diálogo intercultural, caracterizado, sobretudo pelas passagens, mediações e processos tradutórios" (UFMG, 2009, p.19). No que diz respeito à área de Matemática, essa proposta metodológica pode vir a se tornar problemática, na medida em que existam situações nas quais os conhecimentos tradicionais se constituam apenas como pano de fundo para o acesso à matemática escolar, resultando em um processo em que a referência para a sistematização do conhecimento escolar indígena continua sendo o conhecimento "do branco".

Os professores indígenas em formação, por sua vez, são unânimes em enfatizar a importância da escola na preservação, para as novas gerações Xakriabá, dos saberes, práticas e valores de seu povo. Nesse sentido, o Curso também contempla práticas curriculares que proporcionam aos povos que dele participam a recuperação de suas memórias históricas, a reafirmação de suas identidades étnicas e a valorização de suas formas de vida e os conhecimentos a elas associados, que em muito se diferenciam da primazia dada ao uso da escrita para o acesso às informações e aos conhecimentos técnicos e científicos da sociedade nacional não-indígena (PARRA et. al., 2016).

Frente a isso, cabe indagar: no âmbito da Educação Matemática, que tensionamentos entram em jogo quando diferentes racionalidades (a da cultura indígena contemporânea Xakriabá e a da matemática escolar "do branco") co-habitam o espaço da escola indígena de uma de suas aldeias? Quais as implicações desses tensionamentos para a formação intercultural de professores indígenas, na área da Matemática e, em particular, para aqueles que realizam o Curso da UFMG? 
O presente artigo discute essas indagações, tendo a seguinte estrutura: nas próximas seções, apresentamos breves notas sobre as políticas de educação escolar indígena, aspectos importantes do povo Xakriabá, que subsidiam o currículo proposto para suas escolas e descrevemos, também brevemente, o modo como a metodologia do calendário socioecológico está sendo utilizada em uma de suas escolas, a saber, na escola da Aldeia Prata (MG); empreendemos uma revisão de literatura sobre o que vem sendo produzido, no país, na perspectiva da educação intercultural, em particular na área da Educação Matemática, estendendo a discussão para incluir algumas das noções advindas do pensamento tardio de Wittgenstein, que corresponde ao produzido pelo filósofo a partir de sua obra "Investigações Filosóficas" (2004). A seguir, analisamos um episódio vinculado à área da Educação Matemática, que nos permitirá discutir os tensionamentos acima mencionados. O texto finaliza com (in) conclusões sobre o estudo.

\section{O POVO XAKRIABÁ: SEUS MODOS DE VIDA, ORGANIZAC̣ÃO SOCIAL E ESCOLA}

Foi a partir dos anos 2000 que os povos indígenas, no Brasil, se viram, efetivamente, atendidos em algumas de suas reivindicações por amplas políticas de governo de ações afirmativas, direcionadas à diminuição da pobreza, da desigualdade social e de atenção à diversidade. Algumas políticas tiveram impactos imediatos nessa população, promovendo mudanças significativas no seu cotidiano, tais como as de formação de professores para atuar em suas escolas. Outra importante conquista dos povos indígenas, ocorrida em décadas mais recentes, foi a garantia de participação de suas lideranças em órgãos da administração pública direta, como universidades, com poder de decisão. ${ }^{7}$ Essas conquistas produziram mudanças na dinâmica interna das comunidades indígenas, gerando, em alguns casos, conflitos geracionais e o receio dos mais velhos de que os jovens indígenas, envolvidos com as novas bandeiras de lutas, pudessem vir a se afastar das bandeiras históricas de seu povo.

A implantação, no Brasil, de escolas indígenas intercultural e bilíngue foi garantida pela Constituição de 1988 (BRASIL, 1988) e a LDBEN (BRASIL, 1996). Entretanto, mesmo com o respaldo do aparato legal e com a incessante luta desses povos por seus direitos, segue sendo um desafio concretizar uma educação intercultural indígena, que favoreça dinâmicas participativas, os processos de diferenciação pedagógica, a utilização de múltiplas linguagens e o estímulo à construção coletiva. 
No que diz respeito ao povo indígena Xakriabá, suas terras estão localizadas no Município de São João das Missões, no Norte do Estado de Minas Gerais. Abrigando em torno de 7.936 indígenas, em aproximadamente $46415,92^{8}$ hectares de terra (BRASIL, 2017), esse território é caracterizado pela pouca disponibilidade de água. As raízes linguísticas desse povo pertencem ao tronco MacroJê, família Jê, subgrupo Akwen, apesar de eles serem falantes do Português, com suas variações linguísticas.

A exemplo de outros povos, a luta pela demarcação do seu Território ocorreu no final da década de 1980, após muitos conflitos. Os documentos oficiais (BRASIL, 2014, p. 31) corroboram os relatos locais sobre como a luta pela posse da terra exigiu a reafirmação da identidade indígena Xakriabá, para se contrapor a questionamentos, por parte dos não-indígenas, sobre a sua "indianidade". Essa luta tem ganhado novos contornos frente aos desafios contemporâneos que os Xakriabá têm de enfrentar, o que os leva a se manterem continuamente mobilizados em defesa de seus direitos.

Atualmente, a Terra Indígena Xakriabá é dividida em, aproximadamente, 32 aldeias, mas devido ao crescimento da população e às mudanças nas atividades econômicas da região, os Xakriabá reivindicam a incorporação de outras áreas, já comprovadas como terras de seus ancestrais (BRASIL, 2014). Além das atividades de artesanato, extrativismo e agricultura de subsistência, introduziuse, recentemente, o trabalho remunerado, em decorrência da ação mais efetiva de órgãos públicos (estaduais, federais e municipais) das áreas da Saúde e da Educação. Há também aqueles que recebem benefícios sociais concedidos pelo governo federal, tais como a Bolsa Família. A cultura tradicional é incentivada em diferentes espaços, como nas Casas de Cultura e nos Pontos de Cultura.

O sistema sociopolítico Xakriabá é baseado em uma liderança hegemônica, advinda de um cacique-geral, com o apoio de lideranças familiares, que exercem o poder em esfera local. Essas lideranças são partícipes das atividades de suas comunidades, principalmente daquelas vinculadas à sua escola. Isso tem favorecido que, desde a sua implantação, a escola indígena Xakriabá esteja engajada na luta para a preservação dos direitos e para a reafirmação de sua identidade.

A implantação da escola pública estadual no território Xakriabá ocorreu em 1997. A gestão da escola Xakriabá é feita pelos próprios indígenas, sendo uma instituição que atua, intensamente, no cotidiano das comunidades e nas lutas para retomada das áreas reivindicadas, participando de noites culturais, manifestações políticas indígenas, assembleias e plantio de roças. 
Em 2009, alguns professores da Aldeia Prata, egressos do Curso promovido pela UFMG, optaram pela implantação em sua escola de um currículo que usa o calendário socioecológico da comunidade como um instrumento teórico-metodológico para organizar as atividades escolares (GASCHÉ, 2004). Isso significa que, em cada tempo desse calendário, docentes e alunos pesquisam e participam de atividades religiosas, rituais, plantio, confecção de artefatos, dentre outras. Os professores orientam os alunos a realizarem entrevistas e rodas de conversa com suas lideranças, com o objetivo de que, ao expressar o fazer cotidiano e a cultura, seja estabelecida uma articulação intercultural do mundo tradicional Xakriabá e do mundo científico/escolar ocidental.

Em entrevistas, seminários e outros espaços de reflexão sobre o trabalho na escola Xakriabá, os professores-estudantes ${ }^{9}$ têm explicitado que a adoção da proposta do "Calendário" favorece a qualificação dos processos de ensino-aprendizagem escolares e das relações sociais na aldeia. Esses avanços são percebidos no fortalecimento do trabalho coletivo, nas trocas de experiências e na valorização de sua cultura, com a socialização de algumas práticas tradicionais junto aos jovens. No entanto, há professores Xakriabá que também apontam "dificuldades de se incorporar a "cultura indígena" em articulação com os saberes acadêmicos" (NUNES; VALADARES; SILVEIRA JUNIOR, 2017, p. 95), para chegar a uma sistematização de conhecimentos que pretende ser intercultural.

Assim, considerando o contexto escolar Xakriabá da Aldeia Prata, em que professores e alunos compartilham da mesma cultura, somos levadas a repensar, no que diz respeito à educação matemática, a perspectiva de interculturalidade subjacente à metodologia do calendário socioecológico (GASCHÉ, 2004), assim como refletir sobre a perspectiva de educação intercultural do Curso, no âmbito de sua educação matemática. Isso porque muitos dos professoresestudantes Xakriabá estão participando desse Curso e suas percepções sobre as práticas escolares, forjadas mediante o método indutivo intercultural, reverberam no que está sendo desenvolvido no Curso.

\section{EDUCAC̣ÃO (MATEMÁTICA) INTERCULTURAL EM QUESTÃO}

A discussão sobre o que tem sido nomeado por educação intercultural vem ganhando força em diferentes partes do mundo, principalmente, em tempos de intensificação de movimentos 
migratórios. Fundamentada nos estudos pós-coloniais e, face a questões contemporâneas emergentes no continente europeu, Layne (2016) afirma que o termo intercultural é usualmente utilizado para qualificar relações, em geral, com posições desiguais em uma dada sociedade, principalmente no âmbito cultural. Ainda nessa direção, mas tendo o contexto latino-americano como cenário, Walsh (2012) considera que as perspectivas de interculturalidade mais frequentes em propostas educativas na América Latina não rompem com os processos históricos de dominação e colonização, destacando três concepções principais de interculturalidade.

Uma primeira é a interculturalidade relacional na qual, segundo a autora, as relações interculturais ficariam reduzidas às relações interpessoais, minimizando conflitos e a assimetria de poder entre as pessoas e os grupos pertencentes a culturas diferentes. A segunda seria a interculturalidade funcional, que, reconhecendo a diversidade e as diferenças culturais, visa à inclusão dos sujeitos na mesma estrutura social já estabelecida e dominante, mas não se ocupa em refletir sobre as causas da assimetria de poder e das desigualdades sociais e culturais, tampouco questionar as "regras do jogo". Walsh (2012) critica essas duas perspectivas de interculturalidade, a primeira historicamente presente na América Latina e a segunda, impulsionada pelas reformas constitucionais e educacionais que tiveram lugar nos anos 1990. Isso porque a autora considera que ambas não rompem com os processos históricos de dominação e colonização. Diferentemente dessas, a autora propõe uma terceira perspectiva de interculturalidade, a denominada por ela de crítica, alinhada à uma perspectiva decolonial, que aponta para um projeto político, social, ético e epistêmico.

Importante referir, também, o enfoque intercultural nãocolonial de Valencia (2015), que compartilha o esforço de desconstrução da colonialidade, mas difere das anteriormente citadas, pois ultrapassa o esforço da crítica. Trata-se de um enfoque que deve ser entendido como uma afirmação autodeterminada e criativa da consciência crítica e de todas as suas dimensões humanas (FLEURI, 2017).

No âmbito da Educação Matemática, a interculturalidade tem sido explorada nas produções brasileiras de ênfase culturalista, principalmente aquelas que se inserem no campo da Etnomatemática (D'AMBROSIO, 1990; FERREIRA, 2006; KNIJNIK, 2006). Especificamente, o tema da interculturalidade foi discutido em Knijnik, Wanderer e Giongo (2010), tendo como principal referência teórica as ideias presentes em "Investigações Filosóficas" (WITTGENSTEIN, 2004). As autoras, ao analisar jogos de linguagem em diferentes formas 
de vida camponesas no sul do Brasil, apontam para os tensionamentos produzidos pelo confronto entre a cultura oral na qual os camponeses são nativos e a cultura alienígena da matemática escolar ocidental, na qual têm sido escolarizados (p. 26). Resguardadas as diferenças culturais e as lutas históricas, poderíamos inferir que as aulas de matemática nas escolas indígenas e aquelas ministradas nos cursos de formação intercultural também são palcos de tensionamentos produzidos pelas culturas indígenas e a cultura escolar de viés eurocêntrica.

As formulações do filósofo austríaco, nesse período, oferecem subsídios paraquesepossarefletirsobrequestõesligadasàinterculturalidade, a partir de uma nova perspectiva (KNIJNIK; WANDERER; GIONGO, 2010). Para empreender essa reflexão, é relevante apresentar, mesmo que de modo breve, algumas noções wittgensteinianas tais como: formas de vida, usos, jogos de linguagem e semelhanças de família.

Em “Investigações Filosóficas", Wittgenstein passa a considerar que não existe uma única linguagem, senão linguagens, no plural, identificando-as com uma variedade de usos, que se referem não só a contextos verbais: "as significações surgem do uso das palavras, medidas por regras, a partir das nossas práticas sociais, dos nossos hábitos, na nossa forma de vida" (CONDÉ, 2004, p. 52). Ao enfatizar a existência de uma multiplicidade de linguagens, Wittgenstein (2004) introduz a noção de jogos de linguagem: "a totalidade formada pela linguagem e pelas atividades com as quais ela vem entrelaçada" (p. 19). Assim, processos como descrever objetos, relatar acontecimentos, construir hipóteses e analisá-las, contar histórias, resolver tarefas de cálculo aplicado, entre outros, são nomeados por Wittgenstein de jogos de linguagem, estando sua produção vinculada à forma de vida na qual têm uso. Desse modo, à noção de uso é atribuída uma dimensão social, "uma instância a partir da qual significações são criadas [...] e os diversos jogos de linguagem são engendrados" (CONDÉ, 2004, p. 48).

Ademais, o filósofo considerará que os jogos de linguagem mantêm entre si relações de parecença, isto é, têm como que um parentesco, o qual denomina por semelhanças de família. Cada um desses jogos teria sua especificidade, mas também guardaria, em diferentes graus, semelhança com outros jogos (quer seja entre os que se vinculam a uma mesma forma de vida ou entre os associados a outras formas de vida).

As posições de Knijnik (2012), construídas com base nas ideias de Wittgenstein, nos levam a considerar que há jogos de linguagem praticados na forma de vida contemporânea Xakriabá que podem 
ser caracterizados como "matemáticos", uma vez que "se parecem" com aqueles praticados na forma de vida escolar ocidental, nas aulas de matemática. Dito de outro modo, percebemos que é possível estabelecer semelhanças entre tais jogos de linguagem matemáticos dessas distintas formas de vida.

Um aspecto que interessa em especial a este artigo é o uso que Knijnik (2012) faz da obra tardia de Wittgenstein, para argumentar sobre a impossibilidade de jogos de linguagem matemáticos praticados em uma forma de vida serem transladados para outra. Se isso fosse possível, não faria sentido falar em se utilizar dos conhecimentos tradicionais da forma de vida contemporânea Xakriabá, mesmo com as diferenças culturais e linguísticas entre índios e não-índios, como estratégia pedagógica para que se construa uma intercompreensão, por meio de práticas que promovam o exercício das faculdades psicológicas universais (GASCHE, 2004, p. 337).

A construção de "uma ponte" entre jogos de linguagem de distintas formas de vida se tornaria, então, inviável. As posições de Parra et. al. (2016, p. 75) são elucidativas, ao argumentar que a "inclusão de aspectos matemáticos da cultura local no currículo escolar não é planejada para construir pontes para facilitar a aprendizagem da matemática ocidental pelos estudantes. Ao contrário, ela é uma estratégia para construir a identidade cultural".

Com base nesse posicionamento, sintonizado com o pensamento de Wittgenstein e com pesquisadores do campo da Etnomatemática (KNIJNIK, 2012, VILELA, 2013), a própria noção de educação intercultural, em suas distintas formulações, poderia ser repensada. Em particular, consideramos que há condições de questionar a ideia de que a educação escolar intercultural indígena, no contexto da educação matemática, poderia ser efetivada pela passagem dos conhecimentos matemáticos tradicionais para os conhecimentos matemáticos escolares (associados àqueles praticados pelos matemáticos) e vice-versa, o que implicaria em cruzar fronteiras de uma forma de vida para a outra.

\section{OS JOGOS DE LINGUAGEM MEDIR A TERRA PRA FAZER A ROÇA NA ALDEIA PRATA XAKRIABÁ}

Nesta seção discutimos o material de pesquisa gerado ao longo da parte empírica da investigação a que se refere este artigo. Ele é constituído por: um vídeo de um trabalho de campo produzido pelos 
professores-estudantes Xakriabá, na Aldeia Prata, dentro do ciclo do "Calendário de acompanhamento da natureza e da vida do povo Xakriabá"10 e de um vídeo de uma atividade realizada nas aulas da Habilitação em Matemática, na qual a professora-estudante que atua na escola da Aldeia Prata apresentou o vídeo do trabalho de campo que fora anteriormente exibido, como parte do estudo de grandezas e medidas; uma entrevista individual em áudio realizada com ela e dois relatórios impressos elaborados pela mesma professora-estudante; uma entrevista coletiva com uma liderança indígena, um professorestudante da Habilitação em Ciências da Vida e da Natureza, a professora-estudante de matemática (autora dos relatórios) e uma professora egressa do Curso, considerada também uma liderança da referida aldeia. Com exceção da entrevista com a professora-estudante Neuza $^{11}$ (que foi somente gravada e posteriormente transcrita), o restante do material de pesquisa foi videogravado e depois o vídeo passou por uma decupagem, isto é, houve uma seleção e recorte daquelas cenas que mais favorecessem o entendimento da sequência de como eram feitas as medidas da roça.

A entrevista coletiva foi realizada após a exibição do vídeo no seminário do PIBID Diversidade. Durante a entrevista coletiva (registrada no vídeo), conversamos longamente sobre o trabalho de campo, esclarecendo os objetivos e o que fora feito na escola antes e depois desse trabalho. A conversa envolveu assistir ao vídeo, para que o que lá ocorrera pudesse ser relembrado em maiores detalhes. A projeção foi feita com pausas, para que os diferentes aspectos, que eram ressaltados, pudessem ser discutidos. A mesma dinâmica foi utilizada na entrevista individual com a professora-estudante Neuza, que ocorreu no ano seguinte à entrevista coletiva. $\mathrm{O}$ vídeo da aula sobre grandezas e medidas do Curso de formação, na Habilitação em Matemática, foi produzido na universidade, após a entrevista coletiva, realizada na aldeia.

\section{DO TRABALHO DE CAMPO E SUA ANÁLISE}

Em maio de 2014, observando os tempos do "Calendário de acompanhamento da natureza e da vida do povo Xakriabá”, os professores da Aldeia Prata sugeriram atividades que envolviam conhecimentos matemáticos, visando trabalhar o que era nomeado por eles de Matemática Xakriabá. ${ }^{12}$ Como explicou a professoraestudante Neuza, essa era a "matemática indígena de antigamente".

Entre essas atividades cotidianas da aldeia, escolheram a "Derrubada da mata grossa e roçada de capoeira" para a discussão 
sobre medidas, com os estudantes do Ensino Médio e dos Anos Finais do Ensino Fundamental. Inicialmente, Neuza analisou com seus alunos noções de grandezas e medidas, utilizando um livro didático. Como usualmente era feito, convidou quatro lideranças locais, respeitadas pelos seus saberes tradicionais Xakriabá, para uma roda de conversa com os estudantes da escola, na qual foram relatadas várias atividades tradicionais que envolvem medidas, incluindo a atividade de "fazer a roça". Trata-se de uma prática que teve e segue tendo destaque na vida do povo Xakriabá, pois ao longo do tempo se constituiu no único modo de sua sobrevivência, estando estreitamente associada à luta pela demarcação de seu território. Devido ao interesse dos alunos em fazer comparações entre o que eles nomeavam por "matemática de hoje" e a "matemática de antes", para a roda de conversa, os estudantes prepararam várias perguntas sobre as formas tradicionais de fazer a medição da terra.

Uma das lideranças, Seu Valdemar, na época da pesquisa com 69 anos, respeitada por sua trajetória de luta nas conquistas dos direitos daquele povo, explicou aos alunos que, para medir a terra para fazer a roça, ele usava seu passo e que 50 passadas suas equivaliam a 50 metros. Os estudantes ficaram surpresos com a relação que fora estabelecida mesmo que não tenham questionado, às lideranças, sua diferença. Ao perceberem isso, os professores que haviam organizado a roda de conversa e as lideranças combinaram de levar os alunos a uma terra para fazer a medição e analisar a afirmação do Seu Valdemar, com o objetivo de "tirar a prova" sobre a medição.

A atividade de campo ocorreu no início de novembro daquele mesmo ano, quando algumas famílias da comunidade já haviam feito o plantio de sua roça. Para manter a proposta inicial, ou seja, conferir a medida da passada do Seu Valdemar com a medida em metros, houve a decisão de usar a terra de uma das lideranças que já havia sido plantada, portanto, já delimitada. No local da medição, a professora-estudante Neuza orientou os alunos a se organizarem em grupos. Um desses grupos acompanharia Seu Valdemar no processo de medição pelas passadas enquanto o outro grupo faria a medição utilizando uma trena graduada em centímetros e metros, sendo este acompanhado por outras lideranças.

Cada um dos grupos fez a medição da terra, que se aproximava do formato de um retângulo. A cada 20 passos, Seu Valdemar parava, fazendo uma marcação com um pedaço de madeira. Os estudantes que o acompanhavam, anotavam em uma prancheta o número de passos dados e o segundo grupo fazia a medição com uma trena de 20 
metros, anotando o resultado obtido. Isso foi repetido para a medição dos 4 lados da terra. Quando encontravam medidas diferentes para um mesmo lado, surgia uma discussão. Os mais velhos justificavam a diferença dizendo que isso ocorria porque a terra "tinha ladeira". Seu Valdemar explicou que "na descida, não dá muita diferença, não. Mas na subida, dá. Porque quando é pra subir tem de esticar o passo".

Após o trabalho de campo, Neuza propôs aos alunos que somassem as medidas dos 4 lados da terra, registradas por cada um dos grupos, para ver se havia ou não diferença. O resultado foi de 410,5 metros encontrados com o uso da trena e 416 "passadas" encontradas pelo grupo coordenado por Seu Valdemar. Como Seu Valdemar afirmara que sua passada equivalia a 1 metro, os alunos chegaram à diferença de 5,5 metros entre os dois resultados. Segundo a professora-estudante, os alunos consideraram ser a diferença somente "uma diferencinha". Seu Valdemar, por sua vez, estava convencido de que na escola estavam mesmo interessados em comprovar que cada uma de suas passadas "não dava metro, não".

Posteriormente, os professores-estudantes Xakriabá exibiram o vídeo do trabalho de campo no seminário do PIBID Diversidade, já mencionado acima, para exemplificar as práticas da escola Xakriabá, desenvolvidas dentro do currículo orientado pelo calendário socioecológico (GASCHÉ, 2004). Na sequência, o mesmo vídeo foi exibido ao conjunto de estudantes do Curso, Habilitação em Matemática, que inclui outros quatro povos indígenas, propiciando a esses estudantes discutir suas próprias práticas tradicionais de medir e as formas como são abordadas em suas escolas.

Uma primeira análise desse episódio nos levou a concordar com os professores-estudantes, quando esses afirmaram que a prática de medição retratada no vídeo foi somente uma comparação entre a medição com passos, chamada por eles de "matemática de antes", e a medição com a trena, que denominavam "matemática de hoje". Em um registro wittgensteiniano, isso se expressaria do seguinte modo: os professores estabeleceram semelhanças de família entre um jogo de linguagem matemático "de antes", tradicionalmente indígena, e um outro, praticado na forma de vida da matemática escolar do Ocidente. Havia, por exemplo, uma diferença de resultados: O obtido no jogo de linguagem matemático indígena não coincidia com aquele resultado "exato", obtido pelo jogo da matemática escolar. Ele produziu resultados aproximados, "inexatos". Mas, como aponta Wittgenstein, no aforismo \88, de "Investigações Filosóficas": inexato não significa sem utilidade. O filósofo escreve: 
'Inexato' é, na verdade, uma censura e 'exato' é um elogio. E isso quer dizer: o inexato não atinge o seu alvo tão perfeitamente como o mais exato. Depende, pois, do que chamamos 'o alvo'. Sou inexato se não indico com precisão métrica a que distância o sol está de nós, e se não indico ao carpinteiro com precisão milimétrica a largura da mesa? Não está previsto um ideal de precisão, nem sabemos que ideia fazer disso - a não ser que você mesmo estipule o que deve ser denominado assim. Mas vai ser difícil para você encontrar uma tal estipulação, uma que o satisfaça. (WITTGENSTEIN, 2004)

Os resultados "inexatos" - mas úteis aos indígenas da Aldeia Prata - são considerados pelos matemáticos, muitas vezes, como "erros". Mas, como escreve Foucault, "talvez não haja erros em sentido estrito porque o erro só pode surgir e ser decidido no interior de uma prática definida" (FOUCAULT, 2001, p. 33). O jogo de linguagem de medir a terra pra fazer a roça, quando examinado na contingência da forma de vida dos Xakriabá, da Aldeia Prata, à qual está associado, não apresenta erro algum "no sentido estrito". Por ser útil para a tomada de decisão sobre práticas de cultivo e, ademais, por não requerer a trena como instrumento de medida, os indígenas não desqualificam esse seu saber regional, local.

Em um segundo momento, ao entrevistar Seu Valdemar, obtivemos elementos que nos levaram a avaliar que o episódio não se restringia somente à comparação entre resultados obtidos pela prática de dois jogos de linguagem matemáticos diferentes. Foi com a chegada da escola, na aldeia, e a tomada de contato com matemática escolar eurocêntrica que os Xakriabá começaram a perceber semelhanças entre suas práticas tradicionais de contar, medir, quantificar e aquelas transmitidas pela escola. Ao perceberem essas semelhanças, os Xakriabá passaram a adjetivar essas suas práticas de matemáticas. O trabalho com o "Calendário" abriu maior espaço para que os conhecimentos tradicionais circulassem no currículo escolar, levando à identificação de um conjunto de jogos de linguagem matemáticos que passaram a ser nomeados por eles de Matemática Xakriabá.

Nos jogos de linguagem praticados na forma de vida escolar ocidental, de matriz eurocêntrica, o medir é praticado por meio de comparação de grandezas: definida a grandeza a ser medida, toma-se outra grandeza, de mesma natureza, como padrão de comparação, a fim de medir a primeira, estabelecendo-se uma equivalência entre elas. É escolhida, então, uma unidade que servirá de padrão para a grandeza a ser medida em qualquer outra situação; o número de repetições desse padrão será a medida da grandeza em questão. Finalmente, são buscados modos de comunicar ou socializar essa medida, usualmente 
de forma escrita, com a utilização de um tipo de registro que é entendido por toda a comunidade, com base em regras, que conformam uma gramática, isto é, uma racionalidade, que produz (e é produzida por) uma determinada forma de vida e, como tal, é situada.

A detalhada descrição, acima apresentada, põe em questão a pretensa "universalidade" dos jogos de linguagem que conformam a matemática escolar. Isso porque, ao descrever as regras que instituem os jogos de linguagem de medir, na forma de vida escolar, é evidenciado o caráter contingente desses jogos, isto é, seus estreitos vínculos com a racionalidade que marca essa específica forma de vida, com suas regras do formalismo e da abstração. $\mathrm{Na}$ medida em que, pelo menos no ocidente, os jogos de linguagem matemáticos transmitidos na forma de vida escolar - instaurada pela Modernidade e hoje hegemônica - estão "em todo lugar", isto é, afora peculiaridades, são praticados pelas instituições escolares que habitam o mundo globalizado, tem-se a ilusão de que são "universais". No entanto, eles são, na melhor das hipóteses, "internacionais" (BORBA, 1991, p. 40). Este é um ponto importante a ser observado, uma vez que essa "pretensa universalidade" pode nos levar a considerar que a matemática escolar não diz respeito a uma particular forma de vida. No entanto, como antes argumentamos, os jogos de linguagem matemáticos próprios da forma de vida escolar são contingentes, uma vez que são produzidos por regras muito específicas, a saber, aquelas vinculadas ao formalismo e à abstração.

Também tem um caráter contingente o jogo de linguagem medir a terra pra faz̧er a roça, praticado na forma de vida Xakriabá da Aldeia Prata, uma vez que está estreitamente vinculado a essa forma de vida. De acordo com Souza, Ribeiro e Souza (2012), a medição ocorre somente após os meses de julho a agosto, dependendo do clima, das chuvas, pois só pode ser praticado quando a natureza dá sinais de que já é tempo de preparar a terra para plantar. Nesse tempo, o trabalho é organizado em forma de ajuntamento (mutirão) e toda a família se reúne para ajudar: homens, mulheres, crianças.

Os homens participam de todas as etapas da roça, as mulheres preparam os alimentos para os ajuntamentos, ajudam a preparar o aceiro, semear as sementes, tampar as covas e fazer a colheita; as crianças ajudam a semear, tampar as covas e a colher. Os homens marcam a terra em que a roça vai ser feita, usando pedaços de madeira ou cerca de arame. Como ensinado por Seu Valdemar, um padrão para fazer esta medida é o passo. Depois da terra delimitada para o 
plantio, é feita a derrubada das árvores altas e dos troncos grossos. A medida da terra coincide com a quantidade de sementes disponível, definida pelos homens, usando a referência "prato". ${ }^{13}$

Enquanto na forma de vida Xakriabá medir a terra pra fazer a roça destina-se a marcar os limites para fazer o plantio e proteger a roça dos animais, na forma de vida escolar ocidental mede-se para aprender o que é medir e se apropriar dos procedimentos para que a medição se efetive. Mede-se para aprender uma gramática, pois essa medição pode ocorrer independentemente do que se mede e em qualquer momento da vida cotidiana escolar, desde que alguns pré-requisitos respeitem a lógica interna dessa prática de medir. Podemos perceber, contudo, que medir para fazer a roça Xakriabá pressupõe uma unidade de referência (padrão) que também é usada para comparação de grandezas, da mesma forma como é feito na prática escolar. A diferença é que a primeira não se preocupa em usar, necessariamente, grandezas de mesma natureza para medir uma a outra, isso pode ou não acontecer. Como vimos, a superfície a ser plantada é medida pelo volume de sementes, balizado em um prato de medir (celamim), enquanto o perímetro da terra é definido "por passos". No primeiro exemplo, as grandezas são diferentes, já no segundo, ambas são de mesma natureza, como é feito na prática escolar.

No jogo de linguagem da matemática escolar do início da escolarização, medir o contorno de uma superfície resulta na medida de seu perímetro, enquanto a medida da superfície delimitada seria sua área. Os dois jogos de linguagem: medir a terra pra faz̧er a roça e medir uma figura plana possuem semelhanças de família, ainda que se fundamentem em racionalidades diferentes. Medir é fazer comparação de grandezas, toma-se um padrão e criam-se formas de fazer equivalência, de comunicar e de registrar a medida encontrada.

As racionalidades que fundamentam tais jogos de linguagem se diferem entre si porque estão associadas a diferentes formas de vida, a saber, a forma de vida escolar ocidental e a forma de vida não-escolar da Aldeia Prata. O jogo de linguagem da matemática escolar de medir uma figura plana está vinculado a um conteúdo a ser aprendido e, a seguir, exercitado na resolução de problemas previamente elaborados. Esse conteúdo é parte de uma sequência linear previamente definida que compõe a grade curricular, que funciona independentemente dos fenômenos da natureza.

Os processos pedagógicos escolares buscam se ajustar perfeitamente a uma sistematização que leve em conta a relação de 
dependência entre as grandezas e a unidade padrão: comprimentometro; superfície-metro quadrado, etc. Mais ainda: a lógica escolar pressupõe uma sequência de ensino em que primeiro está a medida da grandeza comprimento, com a unidade padrão metro; depois seus múltiplos e submúltiplos, definidos na escala decimal. Procurase ensinar etapa a etapa delimitando muito bem os conceitos e os procedimentos, de modo a diferenciar as dimensões de cada grandeza, a unidade padrão e o tipo de registro que lhe corresponde. Preocupa-se ainda em utilizar instrumentos manufaturados que buscam transmitir confiabilidade à medida, oferecer exatidão e padronização à medida. Trata-se, pois, de jogos de linguagem que são eminentemente da ordem da transcendência, que não estão sujeitos às contingências da atividade humana.

O jogo de linguagem: medir a terra pra fazer a roça, por outro lado, é parte de um ritual Xakriabá que se efetiva para atingir determinados fins. Trata-se de uma prática que se concretiza em um modelo de sociedade no qual as relações econômicas, baseadas na reciprocidade, estão acopladas àquelas que conformam, na contemporaneidade, o mundo globalizado neoliberal. Como explicou a professora-estudante Neuza:

\footnotetext{
Neuza: ele costuma dizer assim: "vou plantar pelo menos para comer verde." ... então não dá para colher e secar... e fazer saca...o que planta ele come... [...] normalmente depois que tira para despesas do ano tira para plantar no próximo....as sementes cada um guarda a sua semente... mas quando chega a hora de plantar...tem coisas que você não tem ... aí você pega no vizinho...vou falar pelo costume lá de casa... minha mãe e meu pai não têm o costume de vender essas coisas ... quando é pouca quantidade...eles não tem o costume de vender... eles tem o costume dessa retribuição...né?
}

Assim, o jogo de linguagem de medir a terra pra fazer a roça está relacionado à sobrevivência da família indígena. Além disso, possui muitos desdobramentos, caso o participante da prática nela não se envolva com intensidade: não se pode, por exemplo, perder o "tempo certo" de demarcar a terra a ser utilizada, pois isso atrasaria todas as outras etapas e comprometeria a colheita, o que teria impactos na vida da comunidade. Trata-se de um jogo de linguagem que ganha sua importância também por transmitir e valorizar um conhecimento que reafirma a identidade Xakriabá. Como consta em um material elaborado por licenciandos desse povo no Curso de formação, para ser utilizado na escola: "Este trabalho de roça é um costume que vem desde os mais velhos e se mantém até hoje" (SOUZA; RIBEIRO; SOUZA, 2012, p. 31). Qualquer negligência nessa prática de medir implicaria em "perder o fio da meada", como explicou Seu Valdemar, quando questionado sobre como aprendeu o conhecimento que repassa para os mais jovens. 
Seu Valdemar: [aprendi] com o pai...o avô...eu costumo dizer que nós tem uma herança...que é de pai para filho de avô para neto e o que eles deixa de herança pra nós é a luta...lutar pelos nossos direito...e aí nós continua...porque pra nós é a organização interna... antiga dos mais velhos... aí nós trabalha para isso não ir abaixo....porque muitas vezes...as emenda das lei vem...mas nós tem nossa proposta interna que nós não pode abri mão...porque se nós abri mão...no dia de amanhã...essas crianças ...onde elas vai ficar? Elas vai perder o fio da meada...

Os Xakriabá, na Aldeia Prata, não medem a terra para fazer roça desvinculados do "tempo da natureza", sem o "ajuntamento" dos membros da comunidade, sem que uns deixem de ajudar os outros, sem a orientação dos mais velhos. Todo esse ritual é o que confere significado ao jogo de linguagem de medir a terra pra fazer a roça. Seus jogos de linguagem de medir são contingentes, associados a algo que deve ser medido. As regras que definem tais jogos seguem a racionalidade de sua forma de vida tradicional, que em muito difere da racionalidade da matemática transmitida na escola eurocêntrica ocidental.

Em síntese, nesta seção analisamos jogos de linguagem matemáticos envolvendo a medição, produzidos por duas distintas formas de vida. Mostramos que um desses jogos de linguagem matemáticos-aquelejogo tradicional praticado, na contemporaneidade, pelo povo Xakriabá, na aldeia Prata - segue regras que são da ordem da contingência; enquanto o outro jogo - aquele que circula na escola de matriz eurocêntrica - é da ordem da transcendência. Isso pode ser evidenciado, por exemplo, no uso que cada jogo faz de um específico instrumento de medida, a saber, a trena e os passos. Isso implica na obtenção de resultados diferentes para a medida de cada lado e, portanto, no perímetro da "terra pra fazer a roça": com a trena, a medida de cada lado e, por consequência, o perímetro têm um caráter de precisão; com as passadas, essas medidas e o respectivo perímetro apresentam valores que se aproximam do valor obtido com a trena, mas não coincidem. Aqui fica explicitado o caráter contingente daquele praticado atualmente na forma de vida Xakriabá, uma vez que, como explicou Seu Valdemar, o número de passos dados depende da "inclinação do terreno" e o caráter transcendente do jogo de linguagem matemático da forma de vida escolar de matriz eurocêntrica.

Outra semelhança entre esses jogos de linguagem matemáticos, também relacionada à contingência do primeiro deles e à transcendência do segundo, diz respeito ao que é calculado para a determinação da "terra pra fazer a roça". No jogo de linguagem matemático da forma de vida Xakriabá, a medida de uma terra é identificada com o perímetro dessa terra de quatro lados, que não é considerada como uma figura plana, uma vez que os acidentes 
topográficos do terreno são levados em conta em seu cálculo. Por outro lado, na matemática escolar, a medida de uma terra é identificada com a área de uma figura plana de quatro lados, no caso, com um quadrilátero que pode ser modelado como um retângulo. $\mathrm{O}$ fato de, no trabalho de campo, não ter sido calculada a área, e sim o perímetro da terra de quatro lados, pode ter como explicação o interesse do grupo em "comparar a medida obtida pela trena e pelos passos". Portanto, podemos afirmar que cada um desses jogos está associado a um tipo de racionalidade, que institui suas especificidades. No entanto, apesar dessas especificidades, os dois jogos de linguagem matemáticos apresentam semelhanças de família, no sentido dado por Wittgenstein a essa noção. Por exemplo, podemos observar que ambos se servem de grandezas para encontrar a medida de cada lado e, por conseguinte, do perímetro e ambos apresentam como resultado final a soma das medidas de cada lado.

\section{À GUIZA DE UMA (IN)CONCLUSÃO}

A escrita deste texto possibilitou que revisitássemos o trabalho de campo realizado anteriormente e, com o uso de noções advindas da fase tardia da obra de Wittgenstein, buscássemos estabelecer um diálogo com o que vem sendo nomeado por educação intercultural. Focamos nossa atenção nos possíveis tensionamentos que emergem quando diferentes racionalidades (as associadas aos conhecimentos matemáticos tradicionais dos Xakriabá e à matemática escolar "do branco") co-habitam o espaço da escola indígena Xakriabá da Aldeia Prata e como tais tensionamentos reverberam na formação intercultural de professores indígenas e, em particular, para aqueles que realizam a Habilitação em Matemática do Curso da UFMG. O que a seguir apresentamos é fruto desse esforço dialógico, que certamente terá desdobramentos.

Assim como ocorre com a grande maioria dos povos indígenas do país, os Xakriabá da Aldeia Prata, desde há muitas décadas, não vivem isolados do mundo ocidental. Estão cientes de que, para serem bem sucedidos em seus contatos econômicos e sociais, têm a necessidade de se apropriarem de jogos de linguagem de outras formas de vida, em particular, dos jogos de linguagem matemáticos praticados nas formas de vida não-indígenas. Disso decorre a importância que é atribuída, por eles próprios, à escola e à valorização dada àqueles que exercem a função de professor. Como explicou Seu Valdemar, "O 
professor hoje tem o direito de dentro da escola explica pro menino a parte do meio ambiente...que ele tem de preserva...e o respeito com os mais idosos...tudo ele tem de explica...tudo nasce dentro da escola". O diálogo transcrito a seguir aponta para a questão da escola, reforçando a percepção do Seu Valdemar:

Neuza: Esses alunos mais novatos [...] cada ano que passa o povo vai se atualizando no mundo de hoje...então se não for trabalhado na escola vai chegar uma hora que o povo não vai saber mais medir ... assim essa questão...você pegar uma pessoa novata hoje... para ele medir uma roça...se ele não tiver esse conhecimento...ele não vai conseguir.

Pesquisadora: Por que com o conhecimento da escola, somente, ele não consegue?

Neuza: não...só com o conhecimento da escola...do que vem de fora...ele não consegue...[a escola] tem de trabalhar o que está na realidade do aluno.

Como se pode constatar, o diálogo acima evidencia o desejo do povo Xakriabá da Aldeia Prata de que seus conhecimentos tradicionais sejam efetivamente trabalhados na escola, ao mesmo tempo em que consideram relevante trabalhar os conhecimentos "dos brancos", uma posição alinhada com pesquisas, tais como as realizadas por Nunes, Valadares e Silveira Junior (2017), Nascimento (2017) e Mogege (2017).

Ademais, o estudo que realizamos nos levou a perceber que os Xakriabá da Aldeia Prata também desenvolveram modos de resistir à imposição cultural que, sob a égide do imperativo da inclusão e da educação para todos (preconizados na legislação brasileira) instauraram políticas públicas destinadas aos povos tradicionais, que nem sempre têm sido implementadas com o devido cuidado para com seus próprios processos de produção e transmissão, de geração em geração, de seus saberes. De fato, aceitar a chegada da escola "do branco", sem que mediações sejam feitas - no que diz respeito tanto aos conteúdos trabalhados como quanto a seus modos de serem ensinados - seria aceitar que, no limite, a vida da aldeia passasse a ser regida pela racionalidade do mundo ocidental. Como destaca Seu Valdemar, ao falar da diferença entre o ensino dos jovens hoje e antigamente:

Seu Valdemar: eu acho que tem diferença...muitas vezes o avanço deles [alunos] está muito...às vezes eles pensa que é só o que eles aprende no quadro e nos livro que eles vai em frente...mas falta essa parte... que é ensinamento nosso... dos antepassado...ele precisa ter o conhecimento do campo e o que eles é como indígena...para eles não perder aquelas raiz...porque eles aprende até bastante entre as quatro parede ... mas fica uma parte que eles tem de ter e preserva... porque eles sabe que é a organização interna...da luta ...porque você tá lá na cidade...mas aqui no campo...nóis é um professor muito forte. 
A liderança Xakriabá reconhece a força da escola e como, nesse espaço, podem passar a circular novos valores, que modifiquem modos de vida de uma comunidade. Ciente disso, dela se aproxima para que, de algum modo, possa acompanhar e interferir no que ali é vivido por suas crianças e jovens. Há uma atitude de tolerância, por parte das lideranças, para com aqueles que atuam e estudam na escola, como, por exemplo, quando aceitam que não participem de outras atividades da comunidade. Os próprios professores reconhecem que "quem quase não participa do plantio da roça são as pessoas envolvidas na escola” (SOUZA; RIBEIRO; SOUZA, 2012, p. 31).

Há a preocupação de que esses novos conhecimentos possam ter como efeito a desvalorização, pelos jovens, da sabedoria dos velhos. As lideranças mais antigas, como o Seu Valdemar, se movimentam no sentido de se aliarem à escola para garantirem que práticas tradicionais estejam presentes no currículo escolar. Ainda que as novas gerações não tenham necessariamente de vir a praticá-las, haveria a garantia de que os jogos de linguagem tradicionalmente praticados na Aldeia Prata seguiriam circulando na comunidade e, assim, a indianidade Xakriabá (BRASIL, 2014) seria legitimada e, constantemente, reafirmada. Isso é o que ocorre com os jogos de linguagem envolvendo medidas tradicionais. Como ressaltou o professor-estudante Naldim:

\footnotetext{
Naldim: acho que a escola está sendo uma fonte principal para retomar esses costumes...os jovens entenderam que antes havia uma diferença...que não é o que está tendo hoje... [...] Então ... a escola é um caminho muito importante para resgatar esses conhecimentos [tradicionais]...mesmo que às vezes [o aluno] não pratica...mas que a juventude fique sabendo que antes havia uma diferença em tudo.
}

De modo análogo a seu colega, a professora-estudante Neuza também esclareceu, na entrevista individual que concedeu, que, em sua visão, "se a escola não trabalhar as relações entre as medidas de antigamente e as de hoje, muitos jovens na aldeia vão ficar perdidos, pois no cotidiano os mais velhos usam as medidas de ontem".

Como se pode constatar, a valorização dada pelos Xakriabá à transmissão, às novas gerações, dos jogos de linguagem matemáticos "de antigamente" se apoia no fato de que, para eles, tais jogos têm uma importância que abrange as dimensões do cultural, do social, do econômico e do político. O que está em questão, então, é o exame de perspectivas educacionais que tenham potencialidades de direcionar nosso pensar sobre a educação indígena e formular estratégias pedagógicas que, sendo postas em ação, possibilitem dar conta dessa demanda dos Xakriabá, em particular, daqueles que vivem na Aldeia Prata. 
Ao longo do texto buscamos mostrar que valorizar o conhecimento tradicional em suas escolas e conquistar o direito à formação dos professores indígenas configuram-se frentes de luta do povo Xakriabá que abarcam, de modo articulado, o ensinar e o aprender dos jogos de linguagem tradicionais e os praticados na escola "do branco", em particular no que se refere àqueles que podem ser caracterizados como matemáticos. Como discutido anteriormente, com o apoio das ideias wittgensteinianas contidas em "Investigações Filosóficas" (WITTGENSTEIN, 2004), essa articulação ficaria comprometida se os conhecimentos tradicionais fossem simplesmente tomados como "ponto de partida" para estabelecer o diálogo intercultural (UFMG, 2009, p.17). Esse pressuposto, se aproxima do que defende Gasché (2004), ao propor que dois universos cognitivos, conhecimento escolar ocidental e conhecimento tradicional, convivam e contribuam conjuntamente para a produção de conteúdos escolares interculturais.

No entanto, diferentemente do que prevê a proposta do currículo orientado pelo "Calendário socioecológico" (GASCHÉ, 2004), o modo como os Xakriabá implementaram essa proposta na escola da Aldeia Prata, seguindo o "Calendário de acompanhamento da natureza e da vida do povo Xakriabá", mostra que suas lideranças estão igualmente interessadas (mesmo que por razões bastante distintas) em que, na escola, sejam transmitidos seus conhecimentos matemáticos tradicionais e também aqueles pertinentes à matemática escolar eurocêntrica, sendo a transmissão dos primeiros feita com a participação ativa dos mais velhos. Como afirmou Seu Valdemar "... aqui no campo...nóis é um professor muito forte".

Lideranças Xakriabá, como Seu Valdemar, não só colaboram com a escola quando convidados, como sugerem conteúdos da escola ocidental a serem ensinados. Por exemplo, ao ser questionado sobre a reação dos alunos diante dos resultados diferentes obtidos na medição da terra pra fazer a roça, Seu Valdemar chama atenção para a importância de discutir com os jovens as dimensões do território Xakriabá e a contribuição da matemática para fazê-los entender como a extensão de 56000 hectares ganha diferentes significados na disputa com os fazendeiros para manter e reaver a terra.

Seu Valdemar: até isso merece ser explicado para os alunos... muitos alunos não conhece a realidade desse território... acha que essa terra é muita ... pra tirar a diferença nela ... a serra... as grota... os lugares impossive que ninguém pode nem anda...ela se torna muito pouca... porque a terra mesmo onde nóis pode usa... é muito pouco... (grifo nosso) 
$\mathrm{Na}$ entrevista realizada com Seu Valdemar, ele enfatiza a presença de um "conhecimento novo", que está ligado a unidades de medidas agrárias, socializado dentro da aldeia pela escola (na roda de conversa) ou no contato com técnicos e engenheiros que circulam na aldeia. Ao perceber Seu Valdemar estabelecendo uma relação com as medidas agrárias, fomos levadas a pensar que ele buscava legitimar as práticas "de antigamente", ou seja, "a matemática dos passos... da passada".

A realização do estudo apontou para as dificuldades que seriam introduzidas no processo educativo, no âmbito da educação matemática, se uma educação matemática intercultural estivesse ancorada em processos tradutórios, pois circulam, na escola da Aldeia Prata, conhecimentos produzidos segundo diferentes racionalidades. Apoiadas nas ideias tardias de Wittgenstein, conjecturamos sobre a impossibilidade de encontrar qualquer tipo de "tradução" de uma cultura para a outra. Diferentemente disso, consideramos que uma formação intercultural para professores indígenas poderia se constituir em um processo que examinasse as especificidades dos diferentes jogos de linguagem matemáticos, assim como estabelecesse semelhanças de família entre tais jogos. O que está em questão, aqui, é a demarcação clara das diferentes racionalidades que instituem tais jogos, que, do ponto de vista epistemológico, se equivalem, mesmo que, do ponto de vista sociológico - isto é, considerando as assimétricas relações de poder que os instituem - sejam desiguais.

É importante destacar as posições de Gasché (2004), no que diz respeito ao reconhecimento dos conhecimentos científicos e dos conhecimentos indígenas, produzidos segundo lógicas diferentes. Para o autor, o primeiro exige o exercício da lógica conceitual e a reflexão crítica sobre a realidade social e cotidiana próprias da sociedade ocidental, enquanto o último é sempre focado a partir de sua operacionalidade sociocultural, sendo ele expresso verbalmente nos discursos e observável na manipulação dos materiais, nos gestos, nas condutas e atitudes pessoais. Em um processo pedagógico que envolva o formador não-indígena e o aluno indígena, Gasché defende que, apesar das diferenças culturais e linguísticas, em contextos onde haja convergência entre pensamentos é possível que os dois sujeitos se desenvolvam simultaneamente, produzindo o processo formativo esperado, desde que se construa uma "intercompreensão cultural" (SILVEIRA; MORTIMER, 2011). Tal construção ocorreria por meio de práticas que promovam o exercício das faculdades psicológicas universais. Na formulação de Gasché, o que parece ser passível de 
contestação é o modo como as duas diferentes lógicas são descritas. $\mathrm{Na}$ descrição realizada pelo autor, fica evidente sua posição de que, ainda que se busque romper com abordagens coloniais, os conhecimentos indígenas permanecem em posição "inferior". Num patamar superior estariam os conhecimentos científicos, que requerem o exercício da lógica conceitual, como se também os conhecimentos científicos não fossem "sempre focados a partir de sua operacionalidade sociocultural", no caso, a cultura acadêmica eurocêntrica.

Como antes referido, a proposta curricular do Curso de Formação Intercultural para Educadores Indígenas da UFMG tem como princípio pedagógico o diálogo intercultural, que reconhece e valoriza os conhecimentos tradicionais dos povos indígenas. Assim, esse currículo também aponta que "os conhecimentos dos povos indígenas podem ser ponto de partida para estabelecer o diálogo com o conhecimento acadêmico historicamente acumulado, representado pelas grandes áreas de conhecimento no curso" (UFMG, 2009, p. 17). Nesse sentido, mesmo que o adjetivo intercultural sugira/ expresse o compromisso com a promoção de uma formação que seja a "expressão de projetos societários, colocando a escola a serviço da comunidade, do meio social em que ela se encontra situada" (NASCIMENTO, 2016, p. 386), há tensionamentos nesse currículo que impossibilitariam o equilíbrio entre as relações de forças dos diferentes tipos de conhecimentos que circulam na escola, ao promover essa educação intercultural.

Em síntese, a análise do episódio apresentado neste texto nos possibilita afirmar que no processo pedagógico, no âmbito da educação matemática, desenvolvido na escola Xakriabá da Aldeia Prata, associado à sua proposta curricular, seus conhecimentos tradicionais não foram usados como ponto de partida para abordar os conhecimentos "do branco". Parece-nos pertinente, portanto, repensar propostas metodológicas interculturais, como as anteriormente referidas, quer seja no âmbito da formação inicial de professores indígenas, como a que se realiza na UFMG, quer seja em escolas indígenas, como a escola Xakriabá da Aldeia Prata.

\section{AGRADECIMENTOS}

Nossos sinceros agradecimentos às professoras Diana e Neuza, ao professor Naldim e, especialmente, ao Seu Valdemar, liderança Xakriabá da Aldeia Prata, pelos ensinamentos, pela confiança e disponibilidade em coloborar com o nosso trabalho. 


\section{REFERÊNCIAS}

BORBA, M. C. Etnomatemática e Educação (Tradução). Boletim GEPEM, Rio de Janeiro, v. 29 , p. 36-43, 1991.

BRASIL. Constituição da República Federativa do Brasil. Brasília: Senado Federal, Centro Gráfico, 1988.

BRASIL, Lei n 9.394 de 20 de dezembro de 1996. Estabelece as diretrizes e bases da educação nacional. MEC/Brasília, 1996.

BRASIL. Resumo do relatório circunstanciado de reestudo de limites da terra indígena Xacriabá. Anexo. Fundação Nacional do Indio (FUNAI). Diário Oficial da União, Brasília, DF, n. 192, p. 30-36, 06 de outubro 2014.

BRASIL. Fundação Nacional do Indio. FUNAI. Disponível em: <http://www.funai.gov. br/index.php/indios-no-brasil/terras-indigenas>. Acesso em: 10 nov. 2017.

CONDÉ, M. L. L. As Teias da razão: Wittgenstein e a crise da racionalidade moderna. Belo Horizonte: Argvmentvm Editora, 2004.

D’AMBrosio, U. Etnomatemática. São Paulo, SP: Editora Ática, 1990.

FERREIRA, E. S. Os índios Waimiri-Atroari e a Etnomatemática. In: KNIJNIK, G.; WANDERER, F.; OLIVEIRA, C. J. (org.). Etnomatemática: curriculo e formação de professores. Santa Cruz do Sul: EDUNISC, 2006, p. 70-88

FLEURI, R. M. Aprender com os povos indígenas. Revista de Educação Pública. n. 62 (1), p. 277-294, 2016.

FOUCAULT, M. História da Sexualidade I: a vontade de saber. $14^{a}$ ed. Rio de Janeiro: Graal, 2001.

GASCHÉ, J. Niños, maestros, comuneros y escritos antropológicos como fuentes de contenidos indígenas escolares y la actividad como punto de partida de los procesos pedagógicos interculturales: un modelo sintáctico de cultura. Educando en la diversidad, México, 2004.

GOMES, A. M. R.; MIRANDA, S. A. A formação de professores indígenas na UFMG e os dilemas das culturas entre os Xakriabá e os Pataxó. In. CESARINO, P. N.; CUNHA, M. C. (org.). Políticas culturais e povos indígenas. São Paulo: Cultura Acadêmica, v. 1. p. 455-483, 2014.

KINIJNIK, G. Itinerários da Etnomatemática: questões e desafios sobre o cultural, o social e o político na educação matemática. In: KNIJNIK, G.; WANDERER, F.; OLIVEIRA, C. J. (org.). Etnomatemática: curriculo e formação de professores. Santa Cruz do Sul: EDUNISC, p.19-38, 2006.

KNIJNIK, G. Differentially positioned language games: ethnomathematics from a philosophical perspective. Educational Studies in Mathematics, v. 80, p. 87 - 100, 2012.

KNIJNIK, G.; WANDERER, F.; GIONGO, I. M. Educação matemática e interculturalidade: um estudo sobre a oralidade de formas de vida rurais do sul do Brasil. Quadrante (Lisboa), v. XIX, p. 49-69, 2010. 
LAYNE, H. "Contact Zones" in Finnish (intercultural) education. 2016. 82f. Dissertation. University of Helsinki, Faculty of Behavioural Sciences Department of Teacher of Education. Research Report 397, 2016.

MIRANDA, S. A. Saberes emergentes: a pesquisa com professoras indígenas. Trabalho $\boldsymbol{\&}$ Educação. Belo Horizonte, v. 25, n.1, p. 267-280, Jan-Abr., 2016.

MOGEGE. M. Mathematical concepts from community elders. Exploring the connection between ethnomathematical contexts and classroom practices. ETD - Educação Temática Digital. Campinas, SP. v.19, n. 3, p. 667-686, jul./set. 2017. DOI: 10.20396/etd.v19i3.8648368.

NASCIMENTO, R. G. Escola como local das culturas: o que dizem os índios sobre escola e currículo. Revista de Educação Pública. n. 62 (1) , p. 373-389, 2016.

NUNES, C. VALADARES, J. M. SILVEIRA JUNIOR, C. O uso do calendário socioecológico na estruturação do currículo das escolas indígenas: uma proposta interdisciplinar e intercultural. Série-Estudos, Campo Grande, MS, v. 22, n. 45, p. 79-98, maio/ago. 2017.

PARRA, A.; MENDES, J. R.; VALERO, P.; UBILLÚS, M. V. Mathematics education in multilingual context for the Indigenous population in Latin America. In. BARWELL, R.; CLARKSON, P.; HALAI, A.; KAZIMA, M.; MOSCHKOVICH, J.; PLANAS, N.; PHAKENG, M.; VALERO, P.; UBILLÚS, M. V. (ed.). Mathematics Education and Language Diversity. The 21st ICMI Study. Springer, p. 67-84, 2016.

SILVEIRA, K. P.; MORTIMER, E. F. Tradição Maxakali e conhecimento científico: diferentes perspectivas para o conceito de transformação. Revista Brasileira de Pesquisa em Educação em Ciências. Vol. 11, n. 3, p. 9-33, 2011.

SOUZA, E. M. de A.; RIBEIRO, V. F.; SOUZA, S. F. O Plantio da roça na aldeia Prata Xakriabá. In: TOMAZ, V. S. (org.). A Matemática e os saberes indígenas dos povos Xakriabá, Pataxó e Tupinikim. Belo Horizonte: PIBID/FAE/UFMG, p.31-39, 2012.

TOMAZ, V. S. (org.). A Matemática e os saberes indígenas dos povos Xakriabá, Pataxó e Tupinikim. Belo Horizonte: PIBID/FAE/UFMG, 2012.

UNIVERSIDADE FEDERAL DE MINAS GERAIS. Projeto Politico Pedagogico do Curso de Formaçao Intecultural para Educadores Indigenas. FIEI. Belo Horizonte, 2009.

VALÊNCIA, M. A. C. Ojo de jíbaro. Conocimiento desde el tercer espacio visual: Prácticas estéticas contemporáneas en el eje cafetero colombiano. Popayán: Universidad del Cauca, Sello Editorial, 2015.

VILELA, D. Usos e jogos de linguagem na matemática: diálogo entre filosofia e educação matemática. São Paulo: LF, 2013.

WALSH C. Interculturalidad y (de)colonialidad: Perspectivas críticas y políticas. Visão Global, Joaçaba, v. 15, n. 1-2, p. 61-74, jan./dez. 2012

WITTGENSTEIN, L. Investigações filosóficas. Petrópolis: Vozes, 2004. 


\section{NOTAS DE FIM}

${ }^{1} \mathrm{O}$ artigo é fruto de pesquisa desenvolvida por uma das autoras durante seu estágio de pós-doutoramento, no ano de 2016 e aprovada em parecer $n^{\circ} 1.102 .436$ do CONEP, em $27 / 05 / 2015$.

${ }^{2}$ A expressão "jogos de linguagem” se refere à uma noção de Wittgenstein, produzida pelo filósofo em seu livro "Investigações Filosóficas" (WITTGENSTEIN, 2004). Sua discussão, assim como a justificativa sobre a pertinência de caracterizá-los por "matemáticos", é realizada, neste texto, na seção "Educação (matemática) intercultural em questão".

${ }^{3} \mathrm{O}$ primeiro trabalho problematiza a função da escola para os povos indígenas em suas articulações com a cultura local, levando-se em conta as articulações do currículo da escola básica e da formação de professores; o segundo, discute os aspectos da pesquisa como eixo de formação dos professores indígenas e os dilemas da passagem da pesquisa sobre povos indígenas para a investigação com pesquisadores/as indígenas, no âmbito do Curso; o terceiro, discute os desafios vividos pelos professores Xarkiabá na implementação de experiências curriculares do Calendário Socioecológico e aponta as tensões e os impasses dessa proposta na formação dos professores no Curso da Universidade Federal de Minas Gerais.

${ }^{4}$ Ao longo do texto são apresentados elementos dessa perspectiva metodológica, formulada por Gasché, com base em uma experiência com os povos Maya em Chiapas/México.

${ }^{5}$ Utilizamos a expressão “tradicionais" para nos referirmos às práticas culturais dos indigenas Xakriabá em que são mobilizadas crenças, valores, recursos materiais próprios da cultura Xakriabá, diferentemente das práticas escolares ocidentais, de raiz europeia.

"A expressão "matemática do branco" é utilizada pelos licenciandos do curso quando se referem ao conhecimento matemático, de matriz eurocêntrica, usualmente transmitido pela escola, no ocidente.

${ }^{7}$ O Curso de Formação para Educadores Indigenas FIEI-UFMG possui um conselho de lideranças indígenas que participa de sua gestão.

${ }^{8}$ Durante a entrevista, a liderança Xakriabá se referia à área do território como sendo 56000 ha.

${ }^{9}$ Ao longo do texto, utilizamos a expressão professor-estudante para nomear aqueles professores que atuavam na aldeia e, concomitantemente, eram estudantes do Curso de Formação da UFMG, quando a pesquisa foi realizada.

${ }^{10}$ Os professores Xakriabá apresentaram o vídeo no seminário do PIBID Diversidade, realizado em Fevereiro de 2015 na UFMG. O PIBID Diversidade é um Programa de Bolsas de Iniciaşão à Docência para a Diversidade, implementado no país a partir de 2012, com o intuito de induzir e fomentar a formação inicial de professores para o exercício da docência nas escolas indígenas e do campo.

${ }^{11}$ Os nomes usados ao longo do texto correspondem efetivamente aos dos indígenas participantes do estudo. Seu uso teve sua expressa permissão. As abordagens e os instrumentos metodológicos utilizados neste estudo obedeceram aos procedimentos éticos estabelecidos para a pesquisa científica em Ciências Humanas. 
${ }^{12}$ Ressaltamos que a expressão "Matemática Xakriabá” tem sido utilizada por esse povo indígena e, por consequência, por aqueles acadêmicos que com ele trabalham.

${ }^{13}$ Prato neste artigo se refere a uma unidade de medida usada pelos Xakriabá que corresponde a, aproximadamente, $2 \mathrm{~kg}$ de feijão. Segundo Seu Valdemar, 10 pratos de sementes correspondem a uma área plantada de 4 hectares.

Submetido: $12 / 11 / 2017$

Aprovado: 03/08/2018

Contato:

Vanessa Sena Tomaz

Universidade Federal de Minas Gerais

Faculdade de Educação (FaE)

Av. Antônio Carlos, 6627, Pampulha

Belo Horizonte $|\mathrm{MG}|$ Brasil

CEP 31.270-901 